\title{
Muscle Function In Low Back Pain: Is Bigger And Stronger What Matters?
}

\author{
Niladri Kumar Mahato
}

\begin{abstract}
The search for risk indicators for acute or chronic low back pain has been intensified in the last couple of decades. This review summarizes reports and reviews that have investigated the efficacy of predictive risk-factors in low back pain and offers clinicians an overview of the evidence that links the causal relationship between alterations in trunk muscle functional capacity (strength and endurance) and muscle morphology with low back pain (LBP). Primary research articles and reviews evaluating physiological properties of trunk muscles strength and endurance in back pain patients and in normal individuals were searched from the Medline and PubMed databases for this review to explore probable etiological predictors of back pain. The results show that though loss in muscle strength and endurance are commonly observed in patients with LBP, their role in forecasting an acute onset or in predicting chronicity of LBP has been unsatisfactory and equivocal. Attempting to find a single and clear-cut back pain predictor involving muscle strength, endurance may or muscle size may be challenging and information obtained only from one of these variables may not be adequate to explain the spectrum of LBP symptomatology in the patient in the clinical setting. Research indicates that suggesting a direct etiological relationship between weaker back muscles and low back pain may be a very simplistic. Similarly, strong back muscles do not offer guarantee against acute or chronic non-specific low back pain.
\end{abstract}

Key-words: endurance, low back pain, multifidus, power-spectrum, proprioceptive, strength.

J Bangladesh Soc Physiol. 2017, June; 12(1): 41-51 For Authors Affiliation, see end of text.

http://www.banglajol.info/index.php/JBSP

\section{Introduction}

$\mathbf{T}$ he search for risk indicators to predict a first-time occurrence of low back pain (LBP) and/or its recurrence has been intensified in the last couple of decades. The spectrum of this search has spanned from detecting predictive risk factors in musculoskeletal changes ${ }^{1-3}$, alterations in muscle functional capacity (e.g., muscle strength and endurance) ${ }^{4-6}$, and muscle activation patterns $^{7-9}$, to the mapping of neurological ${ }^{10-12}$ and psychological alterati ons ${ }^{13}$ associated with

Received 20 Jan 2017; $\quad$ Accepted 6 June 2017

J Bangladesh Soc Physiol. 2017, June; 12(1): 41-51
LBP. Though loss in muscle strength and endurance are commonly observed in patients with LBP ${ }^{14-19}$, their role in predicting acute onset or chronicity of LBP is still being investigated and debated ${ }^{3,8,14}$. Unlike LBP occurring due to specific spine pathologies and nerve root compression, non-specific LBP (NSLBP) involves a heterogeneous and often undetectable group of etiologies. ${ }^{20}$ Thus, it is challenging to find a single and clear-cut structural or functional parameter that could predict an impending episode of LBP or could, at the least, assess the likelihood of its chronicity. Although the search 
for such a parameter has been suggested to be over emphasized $^{21}$, researchers have argued that there is a need to find objective outcomes that can reliably predict the onset and course of NSLBP. An internet medical database search was conducted by the author to identify articles with criteria for inclusion in the review. The articles obtained from the search was scanned and the data was summarized for information on select physiological parameters of muscle morphology and function in the context of LBP.

\section{Methods}

This brief review was undertaken to summarize information available from literature investigating the efficacy of predictive risk factors for LBP, variables such as alterations in trunk muscle functional capacity, muscle morphology, neurological and psychological adaptations associated with back pain. Searches in Medline and PubMed databases was performed for assessment. Studies investigating the role of muscle properties as etiological predictors of back pain were included in this study. Primary research articles and reviews evaluating physiological properties of trunk muscles in back pain patients and in normal healthy individuals were selected for this review work. Data from these articles were extracted and assessed by the author in August 2014. The search yielded sixty papers that met the inclusion criteria for the search including comparison of other parameters like age, sex, chronicity and the sub-groups of the trunk muscles in the study subjects. Specifically, the extraction of information from the selected articles focused on the role of extensor muscle strength and endurance of different groups of para-spinal muscles as predictors of acute or chronic LBP as well as articles that emphasized on the characterization of muscle physiologic functions in LBP cohorts. Additionally, literature on electromyographic assessment of muscle endurance in sets of healthy and LBP patients was reviewed in this work. Potential factors that could limit the assessment and interpretation of muscle strength and endurance were listed and their relevance as predictors of LBP was analyzed. The search criteria included age, sex, chronicity and trunk muscles sub-groups for comparison.

\section{Results}

The search yielded articles that objectively investigated or reviewed studies indicating results show that though loss in muscle strength and endurance are commonly observed in patients with LBP, their role in predicting acute onset or chronicity of LBP has been equivocal. Essentially, no definite and clear-cut picture of predictors involving muscle strength or endurance for back pain could be found. Results suggest that the need for searching a single, clearcut muscle-related predictor of LBP may be overemphasized, and may possibly be challenging to find in physiological terms. Results from continued research in this field indicate that weaker back muscles may not always possess an etiological relationship with low back pain, and that strong back muscles do not guarantee against the occurrence of LBP.

In the following sections the different aspects of muscle morphology and function will be discussed in context of their etiological relationship with LBP in its acute and chronic forms.

(a) Can extensor muscle atrophy predict LBP? There is a large body of evidence that shows the presence of back muscle atrophy in patients with LBP. This atrophy is often observed specifically at the spinal levels affected by the pain. ${ }^{1,2}$ Chronic and even acute LBP commonly results in atrophy of the small, segmental lumbar multifidus muscles (MF). ${ }^{1,2}$ Usually, one-sided LBP accompanies ipsilateral MF wasting whereas mid-line pain in the spine has been associated with bilateral and, at times, with multi-level wasting in the MF. It has been suggested that this MF atrophy occurs due to paininduced reflex inhibition of the muscle that 
subsequently results in local disuse and atrophy in experimental as well as in clinical LBP conditions. ${ }^{22-26}$ Interestingly, Hodges et al., in a classic experiment, reported that the MF cross-sectional area reduced rapidly within hours of an experimental disc lesion or MF denervation at the L3-L4 disc spaces when compared to sham surgery controls. ${ }^{27}$ In a study involving 50 chronic LBP subjects with unilateral LBP, Hides et al. demonstrated that all the subjects had differences in the cross-sectional MF areas between the two sides, with the muscle being smaller on the painful side ${ }^{28}$. In another study, Hides et al. assessed the natural course of lumbar MF recovery following first-episodes of unilateral, mechanical LBP in 41 adults who experienced LBP for at least three weeks. They observed (in a 10- week follow-up) a dissociation between the recovery of pain, disability and other clinically relevant outcomes relative to that of MF size in study patients who did not receive an intervention. Interestingly, study participants who received an exercise intervention showed a similar response with pain, disability and other clinical outcomes with the exception that their MF muscles hypertrophied and recovered faster. ${ }^{25}$ Accordingly, this study presents contradictory data on whether MF tissue size is a critical contributor to the chronicity of LBP per se.Surprisingly, several studies have shown that acute or chronic LBP is not associated with any significant reduction in the size of the main torquegenerating muscles of the back: the erector spinae (ES) muscle group. ${ }^{1,2,14,23-25}$ Parkkola et a.l measured the cross-sectional areas (CSA) by MR imaging of the trunk extensor muscles (i.e., the MF+ES) at the L4-L5 disc levels and compared them with isometric flexion and extension maximal voluntary contraction (MVC) strengths in 48 chronic LBP patients and 60 normal volunteers aged

J Bangladesh Soc Physiol. 2017, June; 12(1): 41-51
30-47 years. ${ }^{3,}{ }^{29}$ This study concluded that although, on average, the patients had smaller and weaker trunk muscles, the backmuscle size was not related to the strength of the trunk extensors. Parkkola et al. also reported that outcome of changes in paraspinal muscle CSA secondary to strength training were variable and inconsistent relative to the existence of back pain in the subjects tested. ${ }^{29}$ Stokes et al documented that reductions in MF size is significantly more than reductions observed in the ES, both in the context of recent onset and chronic LBP ${ }^{26}$. Accordingly, it appears that a change in muscle size occurring with LBP does not alter the extensor muscle strength per se, nor does it map to the chronicity of the condition.

Limitations in current literature associating extensor muscle size with LBP: It is apparent from the search that there are no data examining whether muscle size predicts the risk of developing a first-time episode of LBP. Longitudinal studies investigating the natural course of LBP have been unable to document any predictive relationship between the changing MF size and the recurrence or chronicity of LBP. Though, one could potentially argue that atrophy secondary to a first occurrence could predispose the spine to LBP recurrence, the counter argument is that this atrophy seen in the MF does not necessarily reduce muscle strength in all cases and even if it does it may not be a reason for recurrence. ${ }^{28}$ The literature on the relationship between LBP and variability in the size of trunk muscles seems to be delimited to the study of reduction in the MF size and does not investigate variability of the ES size as a predictive tool for LBP. Data on ES size in LBP is scant and does not infallibly account for LBP chronicity. Therefore, the predictive role of extensor muscle size in determining acute and chronic LBP is quite limited in its 
scope.

(b) Muscle function changes associated with LBP: Muscle function testing in LBP commonly focuses on investigating the strength and endurance of the para spinal trunk extensor muscles. Below I will discuss both functional outcomes as they relate to LBP.

Muscle strength: Several studies assessing back extensor muscle strength in the chronic LBP population have found back muscle strength to be significantly lower when compared to normal matched controls. ${ }^{16,30-32}$ For instance, Addison et al. quantified back extensor strength in 16 patients seeking hospitalization for chronic LBP and observed significant weakness when compared to age, sex and body weight matched controls. ${ }^{33}$ However, no significant differences were observed when extensor muscle strength in the hospitalized patients in the pain clinic was compared to that with LBP patients seeking care from an orthopedic office outpatient practice. This study concluded that differences in the perception of subjective incapacities in the LBP patients groups (in presence of similar strengths of the back muscles) could be attributed to factors other than muscle function deficiencies. ${ }^{33}$ However, a more recent study by Faber et al. investigated the association between low muscle strength and both future musculoskeletal disorders and long-term sickness absence using regression analyses adjusted for age, gender, smoking, body mass index and physical work demands. This study revealed that low trunk extensor muscle strength does not seem to be a good predictor for musculoskeletal disorders and long-term sickness absence in the general working population ${ }^{34}$. Salminen et al. published a study involving a cohort of 38 asymptomatic controls (matched for age, sex, and school class) and 38 symptomatic 15 -year-old-children suffering from chronic and recurrent LBP to evaluate the predictive role of spinal mobility and trunk muscle strength in the context of LBP recurrence ${ }^{6}$. Although strength and endurance capacities of the trunk extensor and the flexors in LBP were found to be decreased in comparison to the controls, greater spine mobility was observed to be a better prognostic indicator of LBP chronicity than muscle function parameters. In a recent systematic review presenting the results of longitudinal studies on the relation between physical capacity and the risk of musculoskeletal disorders, Hamberg-van Reenen suggested that, due to inconsistent results in multiple studies, evidence for a relationship between trunk muscle strength and the risk of low back pain were inconclusive. ${ }^{35}$ Accordingly, based on the literature, there is minimal evidence that trunk extensor muscle strength is directly related to LBP intensity. Below the possible factors are highlighted that likely contribute to the muscle weakness commonly observed in patients with LBP.

Limiting factors that may affect muscle strength:

i) Pain and tissue damage: Presence of tissue damage, pain or tenderness during strength testing itself may result in observed muscle weakness. Muscle guarding in acute or chronic LBP is mediated through the reflex inhibition of muscle action via the supraspinal neural systems $s^{2,23,28,34}$, and this inhibition would conceptually reduce maximal force generation. ${ }^{31,36,37}$ Nociceptive electrical stimulation at the L2-L3 disc annulus and facet joint saline infusions have been shown to result in inhibition of motor unit action potentials (MUAP) of segmental MF and longissimus (ES) activity in porcine models which provides direct support for this assertion. ${ }^{23,} 24$

ii) Changes in trunk muscle recruitment patterns: Silfies et al. have shown that patients with chronic LBP accompanied by clinical instability, show co-activation of the external oblique and the rectus abdominis muscles during general trunk movements, which conceptually could reduce force output during extension tasks. ${ }^{9}$ Several other 
studies related to back pain and pain around other joints have indicated reduced force generating capacities in the muscles around the joints secondary to altered activation patterns in the muscles. ${ }^{38-41}$

iii) Alterations in sensory perception and cortical representation: It has been documented that prolonged bed rest, chronic LBP related MF atrophy, and persistent nociception all may lead to altered sensory perception as well as cortical misrepresentation. ${ }^{10-11}$ Conflict between motor output and sensory feedback in the backdrop of disrupted proprioceptive representation may intrinsically heighten the activity of the pain network in absence of actual tissue damage. ${ }^{10}$ Thus, muscle strength may be reduced with neurogenic pain associated with chronic LBP even with motor 'intention'. 20

iv) Psychological factors: Fear and anticipation of pain, depression, anxiety and fearavoidance behavior associated with LBP have been documented to result in disuse and muscle dysfunction. ${ }^{13}$

v) Other LBP associated factors: Additionally, LBP is associated with changes in muscle metabolism, ${ }^{42}$ inactivity-induced obesity 32 disc degeneration ${ }^{3}$ and vertebral osteoporosis resulting from deconditioning ${ }^{20,43}$ and disuse of back muscles. ${ }^{2}$ All these issues may confound the outcome of strength testing in LBP patients. In summary, though the association of back extensor muscle weakness with LBP is strong, this relationship cannot be termed mechanistic or predictive of LBP. ${ }^{42}$

Muscle endurance: For the trunk extensor muscles, endurance tests are typically based on the length of time one can hold the unsupported trunk in a prone position or how long they can sustain in pushing back against different degrees of resistances. Sorensen et al. investigated risk indicators for chronic LBP with a step-wise logistic regression analysis of combinations of different risk factors, including back muscle endurance. ${ }^{44}$ This one year follow-up study involving 928 LBP subjects found different risk factors for men and women that could predict first-time or chronic LBP. In the women, low isometric endurance of the back muscle was reported to be a risk factor for first-episode LBP only in combination with factors like epigastric pain and daily smoking. Takala et al. tested mobility of the trunk in forward and side bending tasks, maximal isokinetic trunk extension strength, lifting strength and static back extensor endurance in in 307 asymptomatic no-LBP ) and asymptomatic 123 chronic-LBP patients. ${ }^{4}$ The back-muscle endurance scores could not predict future low back pain in a two-year follow up assessment. However, Alaranta et al. pointed out a predictive association of reduced static back endurance with first-time onset of LBP in a study involving 126 asymptomatic subjects that never had LBP, ${ }^{5}$ as also evidenced by Hupli et al. ${ }^{45}$ The former study calculated the odds ratio of incurring acute LBP in subjects with poor back muscle performance to be 3.4 ( $95 \%$ Confidence Interval, 1.2-10.0) when compared to the participants with good and medium endurance performance. ${ }^{5}$ This study however, seems to have a major limitation in terms of its approach to categorize the participants according to their jobs. This job classification divided the study subjects into two groups, the 'white-collar' and 'bluecollar' jobs despite the study subjects coming from a very diverse range of occupations and therefore being exposed to different degrees of occupational risks for developing LBP. In a study involving 449 men and 479 women, Sorensen attempted to detect risk indicators for LBP over a one year follow-up period. ${ }^{18}$ Back muscle endurance as well as strength was measured in this study. Although the analysis of follow-up questionnaires concluded that men with high isometric endurance were relatively protected from having a first-time experience of LBP, the study was inconclusive on the predictive 
accuracy of the back-endurance scores. Moreover, this study did not account for the occupation or the level of physical activity in the participants, as pointed out in a later report ${ }^{44}$. Jorgenson et al. reported back extensor strength and endurance deficits in chronic LBP patients who were tested in an erect standing posture ${ }^{46}$. This study could retrospectively classify the chronic 53 LBP subjects into three different groups based on the duration of the LBP. However, the predictive value of this parameter was reported to be doubtful. Accordingly, one might say that due to the equivocal nature of the predictive capacity of endurance capacity of the back extensors towards evaluating the chronicity of LBP, back extensor muscle endurance may not be a reliable predictor of LBP onset or a tool for prognostic assessment of chronic LBP.

\section{(c) Electromyographic assessment of muscle endurance:}

One of the more advanced techniques to study muscle endurance is based on analyzing the median frequencies (Mf) of EMG signals from the back muscles collected during endurance tasks (power spectrum (PS) or the power density (PD) analysis). As a muscle contracts towards fatigue, temporal shifts in the Mf can be observed to move toward lower frequencies. Roy et al. and more recently, Davarian et al. demonstrated that Mf analysis of the EMG power density spectrum could reliably measure fatigue of the back-extensor muscles ${ }^{47-49}$. Roy et al. This study analyzed surface EMG in 12 chronic LBP patients and matched controls from multiple back muscles during sustained isometric contractions of the trunk muscles at different force levels of trunk extensions till the task could no longer be performed by the participant ${ }^{48}$. Results from this study demonstrated significant differences in Mf slopes between chronic LBP and control subjects. Additionally, the technique used in this study could retrospectively classify the LBP group $(84 \%)$ and the control group (92\%) when the subjects exerted their muscles at $80 \%$ of their maximum voluntary capacity (MVC) ${ }^{48}$. Biedermann et al. examined EMG power spectrum of the paraspinals to correctly classify normal controls from 'avoider' LBP and 'confronter' chronic LBP patients using MF and iliocostalis lumborum muscle (parts of ES) surface EMG data ${ }^{50}$. MF muscle signals in the 'avoiders' group showed changes towards lower frequencies characterizing early fatigue in the MF. However, group differences were not significant for the ES activity. Thus, Mf analysis of the MF could only retrospectively classify or discriminate between LBP and normal study subjects without any predictive accuracy for the ES activity. Mannion et al. studied 229 pain-free healthy individuals to examine relationship between EMG changes and endurance times of the back-extensor muscles. Thoracic (T10) and the lumbar (L3) regions of the ES muscles were selected to record EMG signals during a prone isometric endurance test ${ }^{51}$. Mf parameters correlated highly with the endurance times. However, Mf gradients were found to be significantly steeper at the lumbar than at the thoracic levels indicating greater fatigability in the former group of muscles. The 208 female participants exhibited significantly higher $(\mathrm{p}<0.05)$ endurance time mean values than men $(142 \pm 55 \mathrm{secs}$ vs $116 \pm 40 \mathrm{sec})$. The females showed correspondingly less steep Mf gradients than the male study subjects. The difference between the male and females Mf slopes were significant for both thoracic $(-0.342 \% / \mathrm{sec}$ in males versus $-0.251 \% / \mathrm{sec}$ in females) and at the lumbar $(-0.463 \% / \mathrm{sec}$ in males versus $-0.272 \% / \mathrm{sec}$ in females) ES regions. Additionally, the males showed significant differences in their Mf slopes compared between the thoracic and lumbar regions (-0.342 thoracic vs $0.463 \% / \mathrm{sec}$ lumbar; $\mathrm{p}<0.05$ ). This study concluded that differences in Mf variability depended on and appeared to be limited by the differences in fatigability in regions within the muscle group. This conclusion points to the potential source of variability that may be introduced in Mf analysis of EMG signals acquired from different regions of the trunk 
muscles. Mannion et al. have also shown that the decline in the Mf and the endurance time also depend on the relative area of type I fiber in the paraspinal muscle. ${ }^{52,53}$ Danneels et al. examined the possible mechanisms of back muscle dysfunction by assessing EMG activity in the stabilizing muscle (MF) and the torqueproducing the iliocostalis muscle (part of ES). ${ }^{54}$ The study aimed to identify whether LBP patients showed altered recruitment patterns during different types of exercise tasks. Normalized EMG activity (as a percentage of MVC) of the MF and the ES were analyzed from 77 healthy subjects and 24 patients with sub-acute and 51 chronic LBP during a coordination, a stabilization and a strengthening exercise performance. The chronic LBP patients displayed significantly lower $(\mathrm{P}<0.05)$ EMG activity of the MF during the coordination exercises indicating that the chronic LBP patients had a reduced capacity to voluntarily recruit the MF while performing a relatively less intense coordination exercise protocol. In contrast, during the stabilization exercises no significant differences between patients and controls were found for the activity of the two muscles. These findings indicated that, during low-load exercises, no insufficiencies in back muscle recruitment were evident in either sub-acute or chronic back pain patients. However, during the strength exercises, activity of both back muscles was significantly lower in chronic LBP patients $(\mathrm{P}<0.05$ and $\mathrm{p}<0.01$ for the MF and ES, respectively) compared to healthy controls. The study concluded that pain, pain avoidance or deconditioning may result in lower levels of EMG activity during intensive back muscle contraction. Accordingly, considering reduced extensor muscle endurance seen in chronic LBP, this MF dysfunction was suggested to be related to the reduction in back endurance. Accordingly, deficits in back muscle endurance in individuals with chronic LBP may be attributed to alterations in specific muscle activation patterns in the back. ${ }^{55}$

J Bangladesh Soc Physiol. 2017, June; 12(1): 41-51
Below the possible factors are highlighted that likely contribute to the reduction in muscle endurance commonly observed in patients with LBP. It should be noted that surface interference EMG data is susceptible to variability associated with imprecise placement of EMG electrodes over the muscles with the data being exposed to cross talk between different paraspinal muscles ${ }^{56-57}$. Fiber-type composition of the muscle and the percent of MVC used for an endurance task are major factors that determine the outcome of the Mf analysis of muscle fatigability both in controls and LBP patients ${ }^{58-59}$.

Limiting factors that may affect muscle endurance assessment:

i) Pain and tissue damage: Presence of pain during endurance testing may hinder muscle performance in patients and decrease motivation levels in the performer.

ii) Muscle activation changes: It has been discussed that chronic back pain may be associated with sub-optimal activation of back muscles during strong sustained efforts of trunk extension.

iii) Endurance testing paradigms: Endurance tests based on prone positioning of the subject versus standing test protocols (with or without additional loading of the spine) may present inconsistent outcomes of holding-times (time to task failures) or EMG assessments for measuring back endurance function. Mannion et al. have shown that endurance capacity in back muscles varied with the level of exertion (based on subjective MVC values) applied by the tested subject. Accordingly, studies using different exertion protocols for endurance assessments may not yield comparable and consistent results when comparing endurance outcomes with the course of LBP.

iv) Choice of back muscle tested: In the light of current evidence, one may question if ES is 
the right candidate to be probed for a meaningful muscle function predictor with Mf analysis since the ES muscle appears to exhibit minimum changes in terms of size, muscle-fiber type switches, and activity associated with LBP.

v) Other LBP associated factors: Additionally, gender differences, pain, fear of pain and motor-control impairments may affect outcomes of back endurance in LBP patients. ${ }^{19}$

\section{Conclusion}

In summary, the take home information generated from this review is that finding or expecting to find a stand-alone predictive role for muscle form and function in determining the onset or occurrence of an acute episode of LBP or assessment of its chronicity may be doubtful. Inclusion of other important parameters like balance testing, motor function assessment and psychological evaluation may be explored to enhance the scope of developing a multimodal predictive matrix to determine occurrence, recurrence and chronicity of LBP. ${ }^{60}$ Also, associating the existence of weak or strong trunk muscles with the presence or absence of a risk of acute or chronic LBP condition respectively, may be an oversimplification.

\section{Conflict of interest: None}

\section{Authors' affiliation}

Niladri Kumar Mahato, Biomedical Sciences and Ohio Musculoskeletal and Neurological Institute353, Irvine Hall, Ohio University, Athens, Ohio, 45701,Email: nm620511@ohio.edu Ph: 812-603-3307; Fax: 740-5972778 .

\section{References}

1. Danneels LA, Vanderstraeten GG, Cambier DC, Witvrouw EE, De Cuyper HJ. CT imaging of trunk muscles in chronic low back pain patients and healthy control subjects. European spine journal : official publication of the European Spine Society, the European Spinal Deformity Society, and the European Section of the Cervical Spine Research Society. 2000;9(4):266-72. PubMed PMID: 11261613; PubMed Central PMCID: PMC3611341.
2. Hides JA, Stokes MJ, Saide M, Jull GA, Cooper DH. Evidence of lumbar multifidus muscle wasting ipsilateral to symptoms in patients with acute/ subacute low back pain. Spine 1994;19(2):165-72. PubMed PMID: 8153825.

3. Parkkola R, Rytokoski U, Kormano M. Magnetic resonance imaging of the discs and trunk muscles in patients with chronic low back pain and healthy control subjects. Spine. 1993;18(7):830-6. PubMed PMID: 8316880.

4. Takala EP, Viikari-Juntura E. Do functional tests predict low back pain? Spine 2000;25(16):212632. PubMed PMID: 10954645.

5. Alaranta H, Luoto S, Heliovaara M, Hurri H. Static back endurance and the risk of low-back pain. Clinical biomechanics. 1995;10(6):323-4. PubMed PMID: 11415574.

6. Salminen JJ, Maki P, Oksanen A, Pentti J. Spinal mobility and trunk muscle strength in 15-year-old schoolchildren with and without low-back pain. Spine. 1992;17(4):405-11. PubMed PMID: 1533731.

7. Ng JK, Richardson CA, Parnianpour M, Kippers V. Fatigue-related changes in torque output and electromyographic parameters of trunk muscles during isometric axial rotation exertion: an investigation in patients with back pain and in healthy subjects. Spine 2002;27(6):637-46. PubMed PMID: 11884912.

8. Linsinski P. Surface EMG in chronic low back pain. European spine journal : official publication of the European Spine Society, the European Spinal Deformity Society, and the European Section of the Cervical Spine Research Society. 2000;9(6):559-62. PubMed PMID: 11189927; PubMed Central PMCID: PMC3611419.

9. Silfies SP, Squillante D, Maurer P, Westcott S, Karduna AR. Trunk muscle recruitment patterns in specific chronic low back pain populations. Clinical biomechanics. 2005;20(5):465-73. doi: 10.1016/ j.clinbiomech.2005.01.007. PubMed PMID: 15836933 .

10. Flor H, Denke C, Schaefer M, Grusser S. Effect of sensory discrimination training on cortical reorganisation and phantom limb pain. Lancet. 2001;357(9270):1763-4. doi: Doi 10.1016/S01406736(00)04890-X. PubMed PMID: WOS:0001 69156200017.

J Bangladesh Soc Physiol. 2017, June; 12(1): 41-51 
11. Clark BC, Mahato NK, Nakazawa M, Law TD, Thomas JS. The power of the mind: the cortex as a critical determinant of muscle strength/weakness. Journal of neurophysiology. 2014;112(12):321926. doi: DOI 10.1152/jn.00386.2014. PubMed PMID: WOS:000346471200018.

12. Moseley GL. Graded motor imagery for pathologic pain: a randomized controlled trial. Neurology. 2006;67(12):2129-34. doi: 10.1212/01.wnl. 0000249112.56935.32. PubMed PMID: 17082465 .

13. Vlaeyen JWS, Crombez G. Fear of movement/ (re)injury, avoidance and pain disability in chronic low back pain patients. Manual therapy. 1999;4(4):187-95. doi: DOI 10.1054/ math.1999.0199. PubMed PMID: WOS:000084972400002.

14. Keller A, Johansen JG, Hellesnes J, Brox JI. Predictors of isokinetic back muscle strength in patients with low back pain. Spine. 1999;24(3):27580. PubMed PMID: 10025023.

15. Taimela S, Harkapaa K. Strength, mobility, their changes, and pain reduction in active functional restoration for chronic low back disorders. Journal of spinal disorders. 1996;9(4):306-12. PubMed PMID: WOS:A1996VF42700006.

16. Mayer TG, Smith SS, Keeley J, Mooney V. Quantification of Lumbar Function .2. Sagittal Plane Trunk Strength in Chronic Low-Back-Pain Patients. Spine. 1985;10(8):765-72. doi: Doi 10.1097/00007632-198510000-00012. PubMed PMID: WOS:A1985AWT1800017.

17. Nicolaisen T, Jorgensen K. Trunk strength, back muscle endurance and low-back trouble. Scandinavian journal of rehabilitation medicine. 1985;17(3):121-7. PubMed PMID: 2932794.

18. Bieringsorensen F. Physical Measurements as Risk Indicators for Low-Back Trouble over a One-Year Period. Spine. 1984;9(2):106-19. doi: Doi 10.1097/ 00007632-198403000-00002. PubMed PMID: WOS:A1984SP84300001.

19. Mannion AF, O'Riordan D, Dvorak J, Masharawi Y. The relationship between psychological factors and performance on the Biering-Sorensen back muscle endurance test. Spine Journal. 2011;11(9):849-57. doi: DOI 10.1016/ j.spinee.2011.08.004. PubMed PMID: WOS:000296276100008.

J Bangladesh Soc Physiol. 2017, June; 12(1): 41-51
20. Wand BM, O'Connell NE. Chronic non-specific low back pain - sub-groups or a single mechanism? BMC musculoskeletal disorders. 2008;9:11. doi: 10.1186/1471-2474-9-11. PubMed PMID: 18221521; PubMed Central PMCID: PMC2266926.

21. Walker BF, Williamson OD. Mechanical or inflammatory low back pain. What are the potential signs and symptoms? Manual therapy. 2009;14(3):314-20. doi: 10.1016/ j.math.2008.04.003. PubMed PMID: 18555728.

22. Hides J, Gilmore C, Stanton W, Bohlscheid E. Multifidus size and symmetry among chronic LBP and healthy asymptomatic subjects. Man Ther. 2008;13(1):43-9. doi: DOI 10.1016/ j.math.2006.07.017. PubMed PMID: WOS: 000253638600005 .

23. Indahl A, Kaigle AM, Reikeras O, Holm SH. Interaction between the porcine lumbar intervertebral disc, zygapophysial joints, and paraspinal muscles. Spine. 1997;22(24):2834-40. doi: Doi 10.1097/00007632-199712150-00006. PubMed PMID: WOS:000071040300006.

24. Indahl A, Kaige A, Reikeras O, Holm S. Electromyographic response of the porcine multifidus musculature after nerve stimulation. Spine. 1995;20(24):2652-8. doi: Doi 10.1097/ 00007632-199512150-00006. PubMed PMID: WOS: A1995TM51200006.

25. Hides JA, Richardson CA, Jull GA. Multifidus muscle recovery is not automatic after resolution of acute, first-episode low back pain. Spine. 1996;21(23):2763-9. PubMed PMID: 8979323.

26. Stokes MJ, Cooper RG, Morris G, Jayson MI. Selective changes in multifidus dimensions in patients with chronic low back pain. European spine journal : official publication of the European Spine Society, the European Spinal Deformity Society, and the European Section of the Cervical Spine Research Society. 1992;1(1):38-42. PubMed PMID: 20054946.

27. Hodges P, Holm AK, Hansson T, Holm S. Rapid atrophy of the lumbar multifidus follows experimental disc or nerve root injury. Spine. 2006;31(25):2926-33. doi: 10.1097/01.brs. 0000248453.51165.0b. PubMed PMID: 17139223 .

28. Hides J, Gilmore C, Stanton W, Bohlscheid E. Multifidus size and symmetry among chronic LBP and healthy asymptomatic subjects. Manual therapy. 2008;13(1):43-9. doi: 10.1016/ 
j.math.2006.07.017. PubMed PMID: 17070721.

29. Parkkola R, Kujala U, Rytokoski U. Response of the trunk muscles to training assessed by magnetic resonance imaging and muscle strength. European journal of applied physiology and occupational physiology. 1992;65(5):383-7. PubMed PMID: 1425640 .

30. Storheim K, Holm I, Gunderson R, Brox JI, Bo K. The effect of comprehensive group training on cross-sectional area, density, and strength of paraspinal muscles in patients sick-listed for subacute low back pain. Journal of spinal disorders \& techniques. 2003;16(3):271-9. PubMed PMID: 12792342 .

31. Hultman G, Nordin M, Saraste H, Ohlsen H. Body composition, endurance, strength, cross-sectional area, and density of MM erector spinae in men with and without low back pain. Journal of spinal disorders. 1993;6(2):114-23. PubMed PMID: 8504222 .

32. Mayer TG, Kondraske G, Mooney V, Carmichael TW, Butsch R. Lumbar myoelectric spectral analysis for endurance assessment. A comparison of normals with deconditioned patients. Spine. 1989;14(9):986-91. PubMed PMID: 2781412.

33. Addison R, Schultz A. Trunk strengths in patients seeking hospitalization for chronic low-back disorders. Spine. 1980;5(6):539-44. PubMed PMID: 6451034.

34. Faber A, Sell L, Hansen JV, Burr H, Lund T, Holtermann A, et al. Does muscle strength predict future musculoskeletal disorders and sickness absence? Occupational medicine. 2012;62(1):416. Epub 2011/10/22. doi: 10.1093/occmed/kqr150. PubMed PMID: 22016340.

35. Hamberg-van Reenen HH, Ariens GA, Blatter BM, van Mechelen W, Bongers PM. A systematic review of the relation between physical capacity and future low back and neck/shoulder pain. Pain. 2007;130(12):93-107. Epub 2007/01/16. doi: 10.1016/ j.pain.2006.11.004. PubMed PMID: 17222512.

36. Holm S, Indahl A, Solomonow M. Sensorimotor control of the spine. Journal of electromyography and kinesiology : official journal of the International Society of Electrophysiological Kinesiology. 2002;12(3):219-34. PubMed PMID: 12086817.

37. McNeill T, Warwick D, Andersson G, Schultz A. Trunk strengths in attempted flexion, extension, and lateral bending in healthy subjects and patients with low-back disorders. Spine. 1980;5(6):529-38. PubMed PMID: 6451033.
38. Morrissey MC. Reflex inhibition of thigh muscles in knee injury. Causes and treatment. Sports medicine. 1989;7(4):263-76. PubMed PMID: 2657965 .

39. Dickx N, Cagnie B, Parlevliet T, Lavens A, Danneels L. The effect of unilateral muscle pain on recruitment of the lumbar multifidus during automatic contraction. An experimental pain study. Manual therapy. 2010;15(4):364-9. doi: 10.1016/ j.math.2010.02.002. PubMed PMID: 20207187.

40. Mannion AF, Dolan P. Relationship between myoelectric and mechanical manifestations of fatigue in the quadriceps femoris muscle group. European journal of applied physiology and occupational physiology. 1996;74(5):411-9. Epub 1996/01/01. PubMed PMID: 8954288.

41. Nelson-Wong E, Alex B, Csepe D, Lancaster D, Callaghan JP. Altered muscle recruitment during extension from trunk flexion in low back pain developers. Clinical biomechanics. 2012;27(10):994-8. doi: 10.1016/ j.clinbiomech.2012.07.007. PubMed PMID: 22877831 .

42. Kovacs KM, Marras WS, Litsky AS, Gupta P, Ferguson SA. Localized oxygen use of healthy and low back pain individuals during controlled trunk movements. Journal of spinal disorders. 2001;14(2):150-8. Epub 2001/04/04. PubMed PMID: 11285428.

43. Lakke SE, Soer R, Takken T, Reneman MF. Risk and prognostic factors for non-specific musculoskeletal pain: a synthesis of evidence from systematic reviews classified into ICF dimensions. Pain. 2009;147(1-3):153-64. doi: 10.1016/ j.pain.2009.08.032. PubMed PMID: 19800735.

44. Biering-Sorensen F, Thomsen CE, Hilden J. Risk indicators for low back trouble. Scandinavian journal of rehabilitation medicine. 1989;21(3):151-7. PubMed PMID: 2529630.

45. Hupli M, Hurri H, Luoto S, Sainio P, Alaranta H. Isokinetic performance capacity of trunk muscles. Part I: The effect of repetition on measurement of isokinetic performance capacity of trunk muscles among healthy controls and two different groups of low-back pain patients. Scandinavian journal of rehabilitation medicine. 1996;28(4):201-6. Epub 1996/12/01. PubMed PMID: 9122647.

46. Jorgensen $\mathrm{K}$, Nicolaisen $\mathrm{T}$. Trunk extensor endurance: determination and relation to low-back 
trouble. Ergonomics. 1987;30(2):259-67. doi: 10.1080/00140138708969704. PubMed PMID: 2953591.

47. Roy SH, De Luca CJ, Casavant DA. Lumbar muscle fatigue and chronic lower back pain. Spine. 1989;14(9):992-1001. PubMed PMID: 2528828.

48. Roy SH, De Luca CJ, Emley M, Buijs RJ. Spectral electromyographic assessment of back muscles in patients with low back pain undergoing rehabilitation. Spine. 1995;20(1):38-48. PubMed PMID: 7709278.

49. Davarian S, Maroufi N, Ebrahimi I, Farahmand F, Parnianpour M. Trunk muscles strength and endurance in chronic low back pain patients with and without clinical instability. Journal of back and musculoskeletal rehabilitation. 2012;25(2):123-9. doi: 10.3233/BMR-2012-0320. PubMed PMID: 22684204

50. Biedermann HJ, Shanks GL, Forrest WJ, Inglis J. Power spectrum analyses of electromyographic activity. Discriminators in the differential assessment of patients with chronic low-back pain. Spine. 1991;16(10):1179-84. PubMed PMID: 1836678.

51. Mannion AF, Dolan P. Electromyographic median frequency changes during isometric contraction of the back extensors to fatigue. Spine. 1994;19(11):1223-9. PubMed PMID: 8073313.

52. Mannion AF, Dumas GA, Stevenson JM, Cooper RG. The influence of muscle fiber size and type distribution on electromyographic measures of back muscle fatigability. Spine. 1998;23(5):576-84. Epub 1998/04/08. PubMed PMID: 9530789.

53. Mannion AF, Dumas GA, Cooper RG, Espinosa FJ, Faris MW, Stevenson JM. Muscle fibre size and type distribution in thoracic and lumbar regions of erector spinae in healthy subjects without low back pain: normal values and sex differences. Journal of anatomy. 1997;190 ( Pt 4):505-13. Epub 1997/ 05/01. PubMed PMID: 9183674; PubMed Central PMCID: PMCPmc1467636.

54. Danneels L, Coorevits P, Cools A, Vanderstraeten G, Cambier D, Witvrouw E, et al. Differences in electromyographic activity in the multifidus muscle and the iliocostalis lumborum between healthy subjects and patients with sub-acute and chronic low back pain. European Spine Journal. 2001;11(1):13-9. doi: 10.1007/s005860100314.

55. Beneck GJ, Baker LL, Kulig K. Spectral analysis of EMG using intramuscular electrodes reveals nonlinear fatigability characteristics in persons with chronic low back pain. Journal of electromyography and kinesiology : official journal of the International Society of Electrophysiological Kinesiology. 2013;23(1):70-7. Epub 2012/08/14. doi: 10.1016/ j.jelekin.2012.07.001. PubMed PMID: 22883392.

56. Dimitrova NA, Dimitrov GV. Interpretation of EMG changes with fatigue: facts, pitfalls, and fallacies. Journal of Electromyography and Kinesiology. 2003;13(1):13-36. doi: 10.1016/ s1050-6411(02) 00083-4.

57. Farina D, Fosci M, Merletti R. Motor unit recruitment strategies investigated by surface EMG variables. Journal of applied physiology. 2002;92(1):235-47. PubMed PMID: 11744666.

58. Mannion AF, Weber BR, Dvorak J, Grob D, Muntener M. Fibre type characteristics of the lumbar paraspinal muscles in normal healthy subjects and in patients with low back pain. Journal of orthopaedic research : official publication of the Orthopaedic Research Society. 1997;15(6):8817. doi: 10.1002/jor.1100150614. PubMed PMID: 9497814.

59. Mannion AF, Dolan P. The effects of muscle length and force output on the EMG power spectrum of the erector spinae. Journal of electromyography and kinesiology : official journal of the International Society of Electrophysiological Kinesiology. 1996;6(3):159-68. PubMed PMID: 20719673.

60. Takala EP. Lack of "statistically significant" association does not exclude causality. The spine journal : official journal of the North American Spine Society. 2010;10(10):944; author reply -5 . doi: 10.1016/j.spinee.2010.07.008. PubMed PMID: 20869009. 